\title{
Hodogram specijalista medicine rada za procjenu psihosocijalnih rizika i mjere za smanjenje stresa na radu
}

\author{
Azra Huršidić Radulović
}

Ordinacija medicine rada, prim. dr. sc. Azra Huršidić Radulović, dr. med., spec. med. rada i sporta, Zagreb

Zelena knjiga („Green Paper“) Europske komisije „Poboljšanje duševnog zdravlja populacije: prema strategiji o mentalnom zdravlju građana Europske unije“ iz 2005. navodi da se u zemljama EU-a za duševne bolesti izdvaja 3-4 \% BDP-a, uglavnom zbog gubitka produktivnosti. Nadalje, u više od 28 \% zaposlenih u EU-u bilježe se znakovi stresa na poslu (1). Koliko je to značajan javnozdravstveni problem pokazuje i podatak da se svake godine duševne bolesti i problemi javljaju u 38,2 \% europske populacije (2).

U radnoj populaciji u pogledu duševnih poremećaja razlikujemo tri velike skupine. Prva skupina radnika ima duševne probleme uzrokovane poslom, a druga ima slične simptome čiji je izvor izvan radnog mjesta. Objema je skupinama iznimno važno radno mjesto radi provedbe rehabilitacije. Treću skupinu čine ljudi koji imaju duševne poremećaje duže vrijeme a nisu dio radne populacije, koje je vrlo važno integrirati u radne procese (3).

„Europski sporazum za mentalno zdravlje i dobrobit“ iz 2008. u središte djelovanja stavlja radno mjesto i navodi potrebu za unapređenjem radnih uvjeta, za stvaranjem radne klime u kojoj će se pridonositi mentalnom zdravlju, s naglaskom na usklađenje rada i obiteljskoga života, za uvođenjem programa za sprečavanje stresa na poslu, za promicanjem zdravlja na radnome mjestu i za podrškom zapošljavanja, rehabilitacije i povratka na posao radnika s duševnim problemima i bolestima (4). Luksemburška Deklaracija ističe važnost radnog mjesta za promicanje zdravlja, jer značajan dio populacije svaki tjedan provodi bitan dio vremena na poslu. Biti zaposlen daje pojedincu status, društveni značaj, svrhu i zadovoljstvo, što pridonosi njegovu zdravlju. Nadalje, na radnome mjestu postoje sustavi koji se mogu iskoristiti za zaštitu i promicanje zdravlja radnika (5).

U novom Zakonu o zaštiti na radu u Republici Hrvatskoj u člancima 51. i 52. uvodi se obveza prevencije stresa na radnome mjestu ili u vezi s radom. Poslodavac je obvezan provoditi prevenciju stresa na radu ili u vezi s radom te

Kontakt: Prim.dr.sc. Azra Huršidić Radulović, dr.med., specijalist medicine rada, Prilaz baruna Filipovića 11, HR-10000 Zagreb, tel: +385 13705 215, E-mail: ordinacija-medicine-rada@zg.t-com.hr izraditi procjenu rizika za psihofiziološke napore na radnim mjestima (6). U Strateškom planu razvoja javnog zdravstva u Republici Hrvatskoj od 2013. do 2015. ordinacije medicine rada istaknute su kao provoditelji pripreme $\mathrm{i}$ implementacije antistresnih i programa socijalnih vještina za rizične radne skupine (7). U europskim se zemljama obveza sudjelovanja specijalista medicine rada u procjeni rizika na radu smatra temeljnom u procjeni stresa povezanog $\mathrm{s}$ radom, poglavito zbog osnovne preventivne uloge medicine rada (8). Specijalist medicine rada kao tvrtkin liječnik koji provodi preventivne preglede (9) dolazi do saznanja o gorućim točkama, na osnovi kojih može dati savjet i poduzeti intervenciju na razini skupine i pojedinca radi provedbe efektivnih mjera, praćenja i kontrole (10). U zemljama Beneluxa i Francuske zakonska je obveza specijalista medicine rada jednom godišnje analizirati psihosocijalne rizike $(11,12)$.

Zbog sve većeg značaja stresa na radu i u vezi s radom, kao i uloge specijalista medicine rada u njegovoj prevenciji, Hrvatsko društvo za medicinu rada Hrvatskoga liječničkoga zbora održalo je 14. veljače 2015. simpozij „Hodogram i alati specijaliste medicine rada za procjenu psihofizioloških rizika na radu i mjere za smanjenje stresa“. Hodogram koji je prikazan na simpoziju sastavljen je u cilju pomoći specijalistima medicine rada i drugim stručnjacima koji će se baviti pitanjima procjene i prevencije stresa na radu $\mathrm{u}$ njihovu svakodnevnom radu (13). Ovdje se donosi detaljniji prikaz tog hodograma (Slika 1) koji je zapravo skup postupaka u tvrtki radi procjene psihosocijalnih rizika $\mathrm{i}$ odabira mjera za smanjenje stresa na radnome mjestu. Hodogram je izrađen na osnovi dostupnih smjernica, algoritama postupaka, iskustava u provedbi antistresnih postupaka u drugim razvijenim zemljama i evaluiranih rezultata provedenih mjera, a prilagođeno tradiciji, resursima i zakonskim odredbama u Republici Hrvatskoj.

\section{Hodogram i alati}

Prema svim objavljenim strategijama, smjernicama i preporukama sprečavanja stresa na radu u zemljama članicama Europske unije, najvažnija je intencija provedba procjene rizika od stresa na radnome mjestu, odabira akcije i njene kontrole, prije svega od poslodavca, zajedno $s$ 


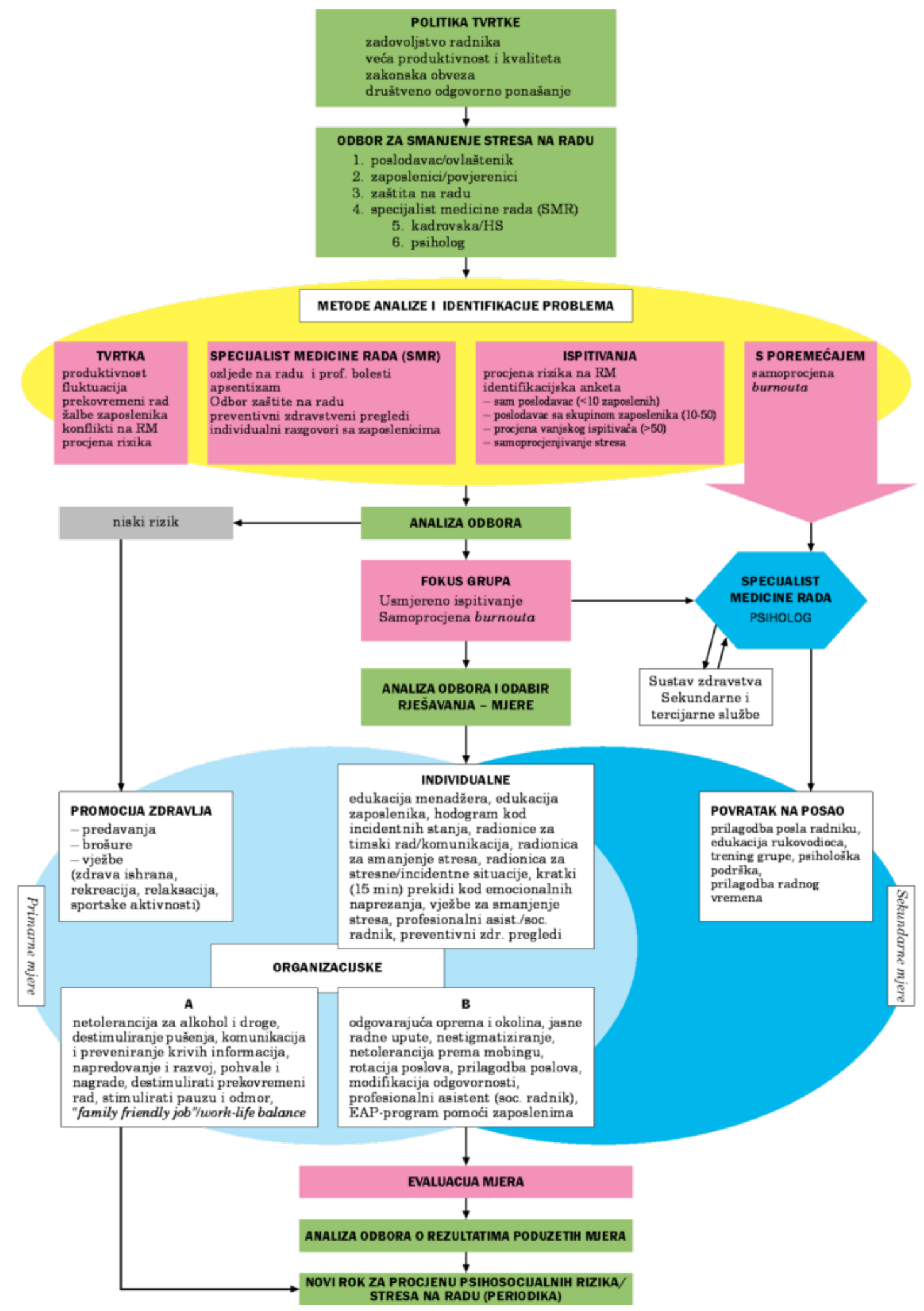

Slika 1 Hodogram specijalista medicine rada za procjenu psihofizioloških rizika na radu i mjere za smanjenje stresa 
radnicima, te uz pomoć stručnjaka/radnika zaduženog za zaštitu na radu i tvrtkina liječnika/specijalista medicine rada (8-12,14).

U svijetu i Europi u primjeni je nekoliko strategija i modela koji se svode na analizu tvrtke i postojećih aktivnosti, poglavito na onu koja se tiče stanja zaštite na radu, zdravstvenoga stanja zaposlenih, odabira najprikladnijeg alata za utvrđivanje psihosocijalnih rizika i identifikacije stresora. Jedna od poznatijih metoda za procjenu svih rizika na radu je SOBANE strategija, koja u nazivu obuhvaća četiri razine: probir, promatranje, analizu i ekspertizu ( $S$-screening, $O B$-observation, $A N$ - analysis i $E$-expertise) (15). S obzirom na razinu stresa tvrtke se prema Karasekovu modelu (Zahtjevi/Kontrola) dijele na četiri tipa: aktivne tvrtke (visoki radni zahtjevi i velika kontrola), pasivne tvrtke (niski radni zahtjevi i mala kontrola), tvrtke s velikim naporima (visoki radni zahtjevi i mala kontrola) i tvrtke s malim naporima (niski radni zahtjevi i velika kontrola) (16).

Svaka procjena rizika na radu, osobito procjena psihosocijalnih rizika, zahtijeva podršku poslodavaca i aktivno sudjelovanje radnika. Stoga „borba protiv stresa“ treba postati politika tvrtke (prvi korak, Hodogram 1). Uz svijest o potrebi borbe protiv stresa i načelne podrške poslodavca, nužno je motivirati i poslodavce i same zaposlenike za sudjelovanje u procjeni psihosocijalnih rizika na radu i mjerama za smanjenje stresa, jer je primarni cilj zadovoljstvo svakodnevnim poslom zaposlenih. Zdravo radno mjesto i zadovoljni zaposlenici imaju veću produktivnost i postižu bolju kvalitetu rada. Prema posljednjim pokazateljima, za poslovodstvo tvrtke u borbi protiv stresa najznačajniji je motiv ispunjenje zakonske obveze, zatim ispunjenje očekivanja radnika i njihovih predstavnika, izbjegavanje inspekcijske kazne, ali i održavanje tvrtkina ugleda te povećanje produktivnosti (17).

Drugi je korak (Hodogram 1) osnivanje odbora za smanjenje stresa na radu, tj. tima koji će identificirati i analizirati stresore, identificirati skupine ili pojedince izložene većim rizicima, tzv. fokus grupe, te odabrati i predložiti mjere za smanjenje psihosocijalnih rizika na radu, a time i za smanjenje stresa. Odbor provodi akcijski plan te donosi odluke o tome što se poduzima, tko poduzima, kako se financira akcija, tko je odgovoran te koji je vremenski rok akcija. Prema tome, vlasnik i/ili poslodavac, tj. njegov ovlaštenik ključni je član odbora za smanjenje stresa na radu. Zakon o zaštiti na radu obvezuje poslodavca provoditi prevenciju stresa na radu, ali i radnici imaju obvezu postupati u skladu s uputama poslodavca i surađivati s poslodavcem radi sprečavanja, uklanjanja ili smanjivanja stresa na radu ili u vezi s radom prema čl. 52 Zakona o zaštiti na radu (6). Zakon o zaštiti na radu u čl. 80 obvezuje poslodavce da ugovore usluge medicine rada i osiguraju radnicima zdravstveni nadzor primjeren opasnostima, štetnostima i naporima tijekom rada u svrhu očuvanja njihova zdravlja. Specijalist medicine rada obvezan je prema Zakonu o zdravstvenoj zaštiti (18) čl. 20 stav 1.t. 4,
7, 8 i 9 procjenjivati radne uvjete te raditi na prevenciji rizika, što je u skladu s potpisanom Konvencijom 161 Međunarodnoga ureda rada (ILO - International Labour Office) (19). Nadalje, Zakon o zaštiti na radu u čl. 34 definira Odbor zaštite na radu i njegove članove: poslodavac ili njegov ovlaštenik, povjerenici zaposlenika, stručnjak za zaštitu na radu i specijalist medicine rada (6). U rad tog odbora uključeni su i zaposlenici koji obavljaju kadrovske poslove te psiholozi.

Različite metode analize $\mathbf{i}$ identifikacije problema (treći korak, Hodogram 1) u primjeni su u analizi poslovanja i rada ne samo tvrtke nego i specijalista medicine rada. Procjena rizika tvrtke zakonska je obveza za poslodavce, a osobito je važna jer daje uvid u stanje zaštite na radu. Proteklih su godina u Europskoj uniji psihosocijalni rizici na radu sve učestaliji, a rad sa zahtjevnim korisnicima svrstava se među vodeće rizike uz zamornu i bolnu poziciju rada te sve druge opasnosti, štetnosti i napore kojima su zaposlenici izloženi (17). Posebno su indikativni podaci iz Nizozemske, gdje je utvrđeno da se najviše stresa javlja u šalterskih službenika, a zatim u učitelja (20). Među 16 najčešćih rizika na radu u Europskoj uniji, na sedmom je mjestu pritisak zbog rokova, na 11. mjestu dugo i neredovito radno vrijeme, a slijede loša komunikacija, nesigurnost posla, nemogućnost utjecaja na posao te diskriminacija zbog spola, godina ili nacije (17). Uz podatke iz tvrtke i zakonski obvezne procjene rizika, podataka i saznanja specijalista medicine rada, na raspolaganju je i niz ispitivanja koji će omogućiti bolji uvid u psihosocijalne rizike na radnome mjestu. Sam poslodavac može identificirati stresore na radnome mjestu svojih zaposlenika pomoću identifikacijskih anketa, ali postoji i mogućnost da to učini vanjski procjenjivač. Veliki broj podataka dobiven je i samoprocjenom stresa zaposlenih, prema kojoj $60 \%$ ispitanih smatra stresnim odgovornost za različite poslove, $52 \%$ prekidanje u radu, $46 \%$ kratke rokove, $45 \%$ ponavljajuće pokrete, $40 \%$ nove zadatke, i to osobito za stariju radnu populaciju (21). Ponuđen je i niz upitnika za samoprocjenu posljedica povišenoga stresa, sindroma izgaranja na poslu (eng. burnout). U Nizozemskoj je u 2010. uzrok sindroma izgaranja na poslu u $22 \%$ slučajeva bio vezan uz organizaciju posla (premalo ili previše zadataka, nejasne obveze i sl.), a na drugom su mjestu bili odnosi na poslu (21\%) (20). Zaposlenike koji već imaju poremećaje ili poteškoće potrebno je uputiti specijalistu medicine rada kako bi sa psihologom, koji je dio tima ordinacije medicine rada, poduzeo potrebne mjere, na primjer uputio zaposlenika u sekundarne i tercijarne zdravstvene službe.

Analiza svih prikupljenih podataka koju su proveli članovi odbora (četvrti korak, Hodogram 1) može imati više ishoda, a najpovoljniji je onaj da je rizik od stresa nizak te nije potrebno poduzimati mjere. Novim Pravilnikom o izradi procjene rizika (22) propisani su uvjeti, način i metoda izrade procjene rizika na radnome mjestu. Nažalost, i pored svih argumentiranih apela, pozivanja na europsku praksu, konvencije i zahtjeve, zakonodavac nije predvidio, 
niti utvrdio kao obvezno, sudjelovanje specijalista medicine rada u izradi procjene, niti je predviđeno razdoblje izrade procjene rizika na radnome mjestu. Procjena rizika revidira se prema novim propisima samo prilikom promjene tehnološkoga procesa, a time je još važnije odrediti razdoblje procjene psihosocijalnih rizika, tj. datum za ponovnu procjenu i analizu odbora za smanjenje stresa na radu. Skupina ili odjel gdje su identifikacija i analiza pokazale veliki rizik, tzv. fokus grupa, zahtijevat će vjerojatno dodatne analize $\mathrm{i}$ ispitivanja te razgovore sa zaposlenicima. Pojedincima će trebati usluge specijalista medicine rada, a u pojedinim slučajevima i psihologa, što predstavlja sekundarno, tj. reaktivno djelovanje na pojedinca koji je pod stresom ili ima rizik od stresa. Primarno ili proaktivno djelovanje u borbi protiv stresa treba biti politika svake tvrtke. Stres na radu ne može se i ne treba potpuno otkloniti s obzirom na to da, izražen $u$ manjoj mjeri, čak pozitivno djeluje na kreativnost, kvalitetu, koncentraciju i produktivnost. Uobičajeni koraci u rješavanju opasnosti, štetnosti i napora na radu nedvojbeno su njihova eliminacija, redukcija, izolacija, kontrola, informacije i savjetovanje.

Odbor nakon analize odabire mjere (peti korak, Hodogram 1) za smanjenje stresogenih čimbenika prema tzv. SMART kriteriju ( $S$ - specific/specifično; $M-$ measurable/mjerljivo; $A$ - attainable/ dohvatljivo; $R$ realistic/realno; $T$ - time-bound/ vremenski ograničeno) (23). Studije u Europskoj uniji upućuju na to da mjere koje se poduzimaju za smanjenje psihofizioloških napora na poslu, kao i promicanje zdravlja, s posljedičnim promjenama u stilu i načinu života, povećavaju produktivnost, a time i profitabilnost, te smanjuju fluktuaciju, jer takva radna mjesta zaposlenici smatraju ,izabranim radnim mjestima“ (24). Promicanje zdravlja na radu primarna je mjera za smanjenje psihosocijalnih rizika na radu. Europska mreža za promicanje zdravlja na radnome mjestu daje potporu stručnjacima i laicima $u$ tome, a na nacionalnoj razini $u$ Republici Hrvatskoj u radu te mreže sudjeluje Hrvatski zavod za zaštitu zdravlja i sigurnost na radu (25).

Organizacijske A mjere ponajprije su primarne mjere za smanjenje stresa na radnome mjestu. Poslodavac i rukovodeći zaposlenici (menadžeri) trebaju stimulirati i davati osobni primjer o potrebi korištenja godišnjeg odmora i radne stanke te destimulirati prekovremeni rad s naglaskom na ravnoteži obiteljskog života i rada. U većim tvrtkama ulažu se sredstva u izgradnju i opremanje vrtića, centara za tjelovježbu, što uz promicanje zdravlja itekako pozitivno utječe na rad zaposlenika. Koliko je važna dobra komunikacija na poslu, napredovanje i razvoj uz pohvale, povezanost s poslom i poslovnim kolegama te osjećaj zaposlenika da svojim radom pridonosi tvrtki u kojoj radi, govori podatak da su zaposlenici koji nemaju i ne osjećaju povezanost s poslom svake godine 3,5 dana duže na bolovanju. Iznimno je značajno istaknuti da je novčana naknada za rad glavni motiv za posao za samo $56 \%$ zaposlenika, a stimulirajuća je tek kada je $20 \%$ iznad prosjeka (26). Rezultati ispitivanja pokazali su da samo 20 \% ljudi uspješno rješava postavljene zadatke ako ih se dekoncentrira uz vrijeđanja i druga ometanja, a s pozitivnim stimulansom i pohvalom njih čak $80 \%$ rješava isti zadatak. Humor na poslu smanjuje stres i poboljšava duševno dobar osjećaj te povezuje radnu zajednicu. Depresija na radu u $30 \%$ osoba javila se zbog odnosa na poslu (20). Organizacijske B mjere su primarne i sekundarne mjere za smanjenje stresa na radnome mjestu. U užem smislu, „organizacijske mjere“ odnose se prije svega na odgovarajuće radno mjesto, uvjete i način rada zaposlenih, primjerice na radno vrijeme, smještaj, rasvjetu, buku, jasne radne upute i sl. U većim tvrtkama u razvijenim europskim i američkim zemljama uvodi se program pomoći zaposlenicima (EAP - Employee Assistance Programme), tj. zaposlenici se za pomoć u problematičnim obiteljskim i radnim situacijama mogu besplatno obratiti profesionalnim asistentima (27). U bivšoj su državi taj posao obavljali socijalni radnici koji su bili zaposlenici tvrtke. Individualne mjere odnose se na mjere za promjenu stavova, načina rada i načina ponašanja. Veoma su bitne promjene u rukovođenju, edukaciji vođenja konflikta, vođenja skupine/tima zaposlenih. U Danskoj, na primjer, menadžeri su duže na bolovanju i podnose najviše zahtjeva za priznavanje profesionalnog stresa (19). Zaposlenici se edukacijama i vježbama uče tehnikama smanjenja stresnog doživljaja te rasterećenja i relaksacije. Dokazana je učinkovitost individualnih mjera u smanjenju apsentizma (28). Značajan dio poslova, poglavito u rastućem uslužnom sektoru, zahtijeva emocionalna naprezanja u radu. $\mathrm{Na}$ tim je poslovima potrebna ,empatija i osjetljivost“", a emocionalni stres ne završava s poslom (27). To su poslovi u kojima se radi identifikacije javljaju frustracija i osjećaj nemoći, poslovi u kojima su radnici suočeni s ekstremnim situacijama, te je poslije posla potreban vremenski odmak. Traumatski događaji poput nesreća i napada na radnome mjestu zahtijevaju posebne mjere, počevši od izrade postupnika za incidentne situacije. Utvrđeno je da su traumatski događaji uvjetovali razvoj posttraumatskog sindroma u čak 87 \% zaposlenih (19). Individualne tehnike za smanjenje stresa i česti 15-minutni prekidi posla, u kojima se obavlja tjelovježba, pokazale su se veoma djelotvornima (27). Individualne mjere na poslu pomažu i u smanjenu stresa čiji je uzrok „kod kuće“, primjerice razvod, selidba, smrt bliskog srodnika.

$\mathrm{U}$ radne procese potrebno je uključiti ne samo zaposlenike s duševnim bolestima i poremećajima, bez obzira na to je li njihov uzrok na poslu ili izvan posla, već i bolesnike s kroničnim duševnim poremećajima koji nisu zaposleni. Povratak na posao radnika s duševnim bolestima i poremećajima zahtijeva niz prilagodbi, počevši od radnog vremena preko edukacije rukovoditelja i treninga skupine zaposlenika u koju se takav radnik uključuje do psihološke potpore.

Evaluacija mjera (šesti korak, Hodogram 1) pokazat će je li odbor odabrao i razradio prikladne mjere $\mathrm{i}$ je li 
njihova realizacija dovela do željenog cilja, tj. do smanjenja psihosocijalnih rizika na poslu te smanjenja stresa na radu ili vezanog uz rad.

Analiza odbora o rezultatima poduzetih mjera (sedmi korak, Hodogram 1) treba odgovoriti i na pitanje o isplativosti mjera. Studije pokazuju isplativost uloženih sredstava za smanjenje rizika od stresa na radu. Ulagaču se na jedan uloženi euro vrati 0,81 do 13,62 eura (24). Rezultati istraživanja iz 2013. podneseni Američkom kongresu ističu da je povrat uloženih novčanih sredstava u smanjenje stresa na radu još i veći u drugoj i trećoj godini ulaganja (29). Svi ti rezultati odredit će novi rok za procjenu psihosocijalnih rizika/stresa na radu (osmi korak, Hodogram 1).

Tradicija $\mathrm{i}$ iskustvo u zaštiti na radu specijalista medicine rada iznimno je snažan element $u$ borbi protiv stresa na radu, što je prepoznato i u europskom projektu „Joint action WP6 - mentalno zdravlje na radu“ (osobni podaci). Nadalje, treba napomenuti i da je mentalno zdravlje obvezni dio edukacije specijalista medicine rada u Republici Hrvatskoj. Uvažavajući sve postignute rezultate i iskustva drugih zemalja, možemo ustvrditi da Republika Hrvatska primjenom svih spomenutih metoda, mjera i postupaka za smanjenje stresa na radu te stečenih iskustava, kao i edukacijom te evaluacijom svih rezultata, uz postojeće zakonske okvire, može ostvariti veliki pomak prema smanjenju stresa na radu i ostvarenju osnovnog cilja

\section{LITERATURA}

1. Health and Consumer Protection Directorate-General. Green Paper, Improving the mental health of the population: Towards a strategy on mental health for the European Union, Brussels 2005 [pristup 16. ožujka 2015.]. Dostupno na http:// www.ec.europa.eu/health/archive/ph_determinants/life style/mental/green_paper/mental_gp_en.pdf

2. Wittchen HU, Jacobi F, Rehm J, Gustavsson A, Svensson M, Jönsson B, Olesen J, Allgulander C, Alonso J, Faravelli C, Fratiglioni L, Jennum P, Lieb R, Maercker A, van Os J, Preisig M, Salvador-Carulla L, Simon R, Steinhausen HC. The size and burden of mental disorders and other disorders of the brain in Europe 2010. Eur Neuropsychopharmacol 2011;21:655-79. doi: 10.1016/j.euroneuro.2011.07.018

3. Fine A, Griffiths J, editors. Joint Action on Mental Health and Well-being. Mental health at the workplace. The SWOT Analysis Report - Context and Key Findings [pristup 16. ožujka 2015.]. Dostupno na http://www.eaad.net/fileadmin/ user_upload/06_JA_SWOT_Analysis_Report_Part_1.pdf

4. European Pact for Mental Health and Well-being "Together for Mental Health and Well-Being" EU High level conference; 12.-13. lipnja 2008., Brussels.

5. The Luxembourg Declaration on Workplace Health Promotion in the European Union, 2007 [pristup 16. ožujka 2015.]. Dostupno na http://www.enwhp.org/fileadmin/rsdokumente/dateien/Luxembourg_Declaration.pdf

6. Zakon o zaštiti na radu. Narodne novine 71/2014; Ispravak Zakona o zaštiti na radu. Narodne novine 118/2014; Uredba o izmjeni Zakona o zaštiti na radu. Narodne novine 154/2014.
7. Strateški plan razvoja javnog zdravstva od 2013. do 2015. Vlada Republike Hrvatske, Ministarstvo zdravlja 2013. [pristup 16. ožujka 2015.]. Dostupno na http://www.zdravlje. hr/programi_i_projekti/nacionalne_strategije

8. [Valutatione e gestione del rischio da stres lavoro correlato. Manuale ad uso delle aziende in attuazione del D.Lgs. 81/08 e s.m.i. INAIL 2011, na talijanskom]. [pristup 16. ožujka 2015.]. Dostupno na http://www.inail.it/internet_web/wcm/ $\mathrm{idc/groups/internet/documents/document/ucm}$ portstg_093254.pdf

9. Federal Ministry of Labour and Social Affairs. Joint Declaration on Mental Health in the Workplace. Bonn: Federal Ministry of Labour and Social Affairs; 2013.

10. HSPS 15 Stress and Resilience. Health, Safety and Wellbeing. Version 5, 2013 [pristup 16. ožujka 2015.]. Dostupno na: http://www.plymouth.gov.uk/hsps15_stress_ and_resilience.pdf

11. [Direction générale Humanisation du travail. Methodes et instruments pour une analyse ergonomique et psychosociale, na francuskom]. Bruxelles: Directione générale Humanisation du travail; 2005.

12. Langevin V, Francois M, Boini S, Riou A. [Évolutions et Relations en Santé au travail (EVREST), na francuskom]. Doc Méd Trav 2011;127:463-5.

13. Huršidić Radulović A. Prijedlog hodograma s alatima specijaliste medicine rada za procjenu psihosocijalnih rizika zajedno s mjerama za smanjenje stresa na radu. U: Simpozij Hrvatskoga društva za medicinu rada "Hodogram i alati specijaliste medicine rada za procjenu psihofizioloških rizika na radu i mjere za smanjenje stresa"; 14. veljače 2015.; Zagreb.

14. RR537 - The suitability of HSE 'srisk assessment process and management standards for use in SMEs'; Health and Safety Executive 2007 [pristup 16. ožujka 2015.]. Dostupno na http://www.hse.gov.uk/research/rrpdf/rr537.pdf

15. Malchaire JB. The SOBANE risk management strategy and the Déparis method for the participatory screening of the risks. Int Arch Occup Environ Health 2004;77:443-50. PMID: 15205963

16. Karasek's Model of Job Strain (R.A. Karasek, 1979) [pristup 16. ožujka 2015.]. Dostupno na http://www.med.uottawa.ca/ courses/epi6181/Course_Outline/Karasek_fn.pdf

17. European Agency for Safety and health at work. Second European Survey of Enterprises on New and Emerging Risks (ESENER-2) First findings. [pristup 16. ožujka 2015.]. Dostupno na https://osha.europa.eu/en/publications/reports/ esener-ii-first-findings.pdf

18. Zakon o zdravstvenoj zaštiti. Narodne novine 150/2008.

19. Konvencija broj 161 o službama medicine rada. Narodne novine - Međunarodni ugovori 2/1994.

20. What recognition of work-related mental disorders? A study on 10 European countries study Report Eurogip [pristup 16. ožujka 2015.]. Dostupno na http://www.europeanforum.org/ documents/24/eurogip_81en_recognition_wr_mental_ disorders_europe.pdf

21. Lohmann-Haislah A. [Stressreport Deutschland 2012, na njemačkom] [pristup 16. ožujka 2015.]. Dostupno na http:// www.baua.de/de/Publikationen/Fachbeitraege/Gd68. pdf? blob=publicationFile

22. Pravilnik o izradi procjene rizika. Narodne novine 112/2014. 
23. Doran GT. There's a S.M.A.R.T. way to write management's goals and objective. Management Rev (AMA FORUM) 1981:70:35-6.

24. Economic analysis of workplace mental health promotion and mental disorders prevention programmes and of their potential contribution to EU health, social and economic policy objectives 2013 [pristup 16. ožujka 2015.]. Dostupno na http://ec.europa.eu/health/mental_health/docs/matrix economic_analysis_mh_promotion_en.pdf

25. The European Network for Workplace Health Promotion (ENWHP) [pristup 16. ožujka 2015.]. Dostupno na http:// www.enwhp.org

26. [Studie zur Job-Motivation zeigt, was Fach- und Führungskräfte in Deutschland zu mehr Leistung antreibt, na njemačkom]. Düsseldorf, Februar 2012 [pristup 16. ožujka 2015.]. Dostupno na http://www.stepstone.de/UeberStepStone/presse/motivation-ist-nicht-kaeuflich.cfm

27. Psychische Gesundheit in der Arbeitswelt - psyGA. [pristup 16. ožujka 2015.]. Dostupno na http://psyga.info/ueberpsyga/das-projekt/.

28. Sockolt I, Kramer I, Badecker W. Effectiveness and economic benefits of workplace health promotion and prevention. iga-Report 13e [pristup 16. ožujka 2015.]. Dostupno na http://www.iga-info.de

29. U.S. Department of Health \& Human Services. Report to Congress on Workplace Wellness. 2013 [pristup 16. ožujka 2015.]. Dostupno na http://aspe.hhs.gov/hsp/13/ WorkplaceWellness/rpt_wellness.cfm 